\title{
Effective Thermal and Mechanical Properties of Short Carbon Fiber/Natural Rubber Composites as a Function of Mechanical Loading
}

\author{
Mostafa Mahdavi $^{\mathrm{a}}$, Ensieh Yousefi ${ }^{\mathrm{a}}$, Majid Baniassadi ${ }^{\mathrm{a}, \mathrm{b}, 1^{*}}$, Morad Karimpour ${ }^{\mathrm{a}, \mathrm{c}}$, \\ Mostafa Baghani ${ }^{\mathrm{a}}$ \\ ${ }^{a}$ School of Mechanical Engineering, College of Engineering, University of Tehran, Iran \\ ${ }^{b}$ University of Strasbourg, ICUBE Laboratory-CNRS, 2 Rue Boussingault, 67000 Strasbourg, France \\ ${ }^{C}$ Department of Mechanical Engineering, Imperial College, London SW7 2AZ, UK
}

\begin{abstract}
Carbon fibers significantly improve thermal and mechanical properties of nanocomposites, and many researchers have focused their studies on determining the effective thermal and mechanical properties of these composites. Much effort has gone into determining how mechanical loading changes the effective properties of the nanocomposite, and studying its behavior under further mechanical loading. In the present study, a computer simulation of three different volume fractions of carbon fibers in natural rubber was subjected to eight loading scenarios, each, to study the effect of loading conditions on the effective thermomechanical properties of the nanocomposites. Results suggest that mechanical loading can improve the effective thermal conductivity and increase the elastic modulus of the nanocomposite.
\end{abstract}

Keywords: Thermal Conductivity, Elastic Modulus, Poisson's Ratio, Short Carbon Fiber, Nanocomposite, Mechanical Loading

\footnotetext{
* School of Mechanical Eng. College of Engineering, University of Tehran, Tehran, Iran E-mail: m.baniassadi@ut.ac.ir

Tel. +98 (0) 2161119935
} 


\section{Introduction}

Carbon fibers are regarded as multifunctional fillers for polymers, improving their properties. Carbon fibers have a wide range of aspect ratios that can be used for different purposes such as thermal conductivity and elastic modulus enhancement. These properties make them an excellent filler for polymers to increase their thermal and mechanical properties [1-3]. Carbon nanotubes (CNTs) come in two varieties: Single Wall Nanotubes (SWNT) consisting of a single sheet of graphene rolled into cylindrical form, and Multi Wall Nanotubes (MWNT) composed of multiple concentric SWNTs [4, 5].

Experimental studies show that CNTs have high thermal conductivity, more than 2000 (W/m.K) for SWNTs and MWNTs [6-9]. Due to their superior properties, nanocomposites are popular in many engineering fields such as aerospace and biomechanics [10-12]. CNTs have been shown to improve stiffness, Young modulus, electrical conductivity, thermal conductivity and strength of polymers [13-16]. CNT-polymers are used in electrical devices and electronic systems that benefit from high conductivity [17, 18]. The effect of Short Carbon Fibers (SCFs) on the mechanical properties of epoxy resin is compared against that of CNTs by Zhang et al. [19].

In the application of CNTs as fillers in polymer, the challenge lies in achieving uniform nano-particle dispersion, and formation of a strong adhesion at the particle matrix interface [20]. The main commercial production methods are solution mixing, melt processing, and in situ polymerization.

Determination of effective properties of nanocomposites is of outmost importance when it comes to choosing the material for different applications. Nan et al. [21] developed the effective medium approach (EMA) for calculating the effective thermal conductivity of carbon nanotubes. Baniassadi et al. [22] have used statistical continuum theory for studying the effective thermal conductivity of carbon nanotube composites. They used two-point and three-point probability functions to consider the orientation, shape and distribution of the two phases and used the strong-contrast approach to predict the effective thermal conductivity of carbon nanotube composites. This method does not consider the interaction between the nanotubes and the polymer matrix. Benveniste [23] presented Mori-Tanaka theory for 
calculation of effective thermal conductivity of nanocomposites. One of the popular modeling techniques which is used for simulation of nanocomposites is the finite element method. In this method, the geometry of nanocomposites can be easily imported to a different simulation software. In this method a representative volume element (RVE) was used for presenting nanocomposite in the simulation. Mortazavi et al. [24] have used three different approaches for modeling two-phase random composite materials, which show the advantages and disadvantages of them.

Mazrouei et al. [25] have investigated the effect of mechanical loading on the effective thermal conductivity using Mori-Tanaka approach. It was reported that the effective thermal conductivity increases in the direction of loading. The present study is focused on further investigating this phenomenon using numerical models. FE models of varying volume fractions of SCFs in the natural rubber matrix are used to study their thermomechanical properties. The novel challenge for present research is to link mechanical and thermal properties. Calculation has been performed on a 500 cores high performance machine. The behavior of thermal conductivity and changing of alignment of SCFs are studied. It is observed that mechanical loading increases alignments and consequently increases thermal conductivity. The elongation of sample is another phenomenon which can decrease thermal conductivity, in this study this opposite phenomenon is also studied.

\section{Material Specification}

The properties of pitch-based short carbon fibers (M-2007S) were. This filler has different aspect ratios (minimum6.2) with density value of $1.6\left(\mathrm{~g} / \mathrm{cm}^{3}\right)$, modulus of elasticity of $35 \mathrm{GPa}$, and thermal conductivity of $100(\mathrm{~W} / \mathrm{m} . \mathrm{K})$ [26-28]. These fillers were used to reinforce natural rubber as the matrix. Three different volume fractions of carbon fiber $(1 \%, 1.5 \%, 2 \%)$ were each subjected to eight loading scenarios. Natural rubber has a density of $0.93\left(\mathrm{~g} / \mathrm{cm}^{3}\right)$, modulus of elasticity of $1.5 \mathrm{MPa}$, and thermal conductivity of $0.14(\mathrm{~W} / \mathrm{m} . K$ ) [29, 30]. Table 1 shows the process which has been done in this study. 
Table 1. The process which has been done in this study

\begin{tabular}{|c|c|c|c|c|c|}
\hline \multicolumn{3}{|c|}{ Samples which have been used } & \multicolumn{2}{|c|}{$\begin{array}{l}\text { The loadings which were applied } \\
\text { to samples }\end{array}$} & Results \\
\hline $\begin{array}{c}1 \text { percent volume of } \\
\text { SCFs in natural } \\
\text { rubber }\end{array}$ & $\begin{array}{c}5 \text { random } \\
\text { distributions } \\
\text { of SCFs in }\end{array}$ & $\begin{array}{c}15 \\
\text { samples } \\
\text { for three }\end{array}$ & $\begin{array}{c}\text { Mechanical } \\
\text { loading }\end{array}$ & $\begin{array}{c}8 \text { strains }(3.33 \%, \\
5 \%, 6.66 \%, 8.34 \%, \\
10 \%, 11.67 \%,\end{array}$ & $\begin{array}{l}\text { For each of } \\
15 \text { samples, } \\
\text { the behavior }\end{array}$ \\
\hline $\begin{array}{c}1.5 \text { percent volume } \\
\text { of SCFs in natural } \\
\text { rubber }\end{array}$ & $\begin{array}{l}\text { the matrix } \\
\text { were } \\
\text { generated for }\end{array}$ & $\begin{array}{c}\text { volume } \\
\text { fractions } \\
\text { were }\end{array}$ & & $\begin{array}{c}13.33 \% \text {, and } 15 \% \\
\text { strain) were applied } \\
\text { to each sample. }\end{array}$ & $\begin{array}{c}\text { of thermal } \\
\text { conductivity, } \\
\text { elastic }\end{array}$ \\
\hline & $\begin{array}{l}\text { each volume } \\
\text { fraction }\end{array}$ & generated & $\begin{array}{l}\text { Thermal } \\
\text { loading }\end{array}$ & $\begin{array}{c}\text { After applying } \\
\text { mechanical }\end{array}$ & $\begin{array}{l}\text { modulus and } \\
\text { Poisson's }\end{array}$ \\
\hline $\begin{array}{l}2 \text { percent volume of } \\
\text { SCFs in natural } \\
\text { rubber }\end{array}$ & & & & $\begin{array}{c}\text { loading, in each } \\
\text { strain, thermal } \\
\text { loading was applied }\end{array}$ & $\begin{array}{c}\text { ratio was } \\
\text { illustrated in } \\
\text { every strain }\end{array}$ \\
\hline
\end{tabular}

\section{Methodology}

The representative volume elements (RVEs) have been simulated using the commercial FEA package ABAQUS. A MATLAB code was developed to generate models with volume fractions of $1 \%, 1.5 \%$, and $2 \%$. Monte-Carlo algorithm was used for generating random coordinates for the fillers resulting in isotropic RVEs [31]. Five statistically equivalent models were generated for each set of parameters of each volume fraction in order to ensure that the reported results are not affected by the randomness of the SCF distribution within the RVE.

In this study the effect of mechanical loading (at 3.33\%, 5\%,6.66\%, 8.34\%, 10\%, $11.67 \%, 13.33 \%$, and $15 \%$ strain) on the effective thermal conductivity of models with three different volume fractions (five models were generated for each volume fraction) was investigated. 
Based on the proposed algorithm a random point is selected as one end of SCF axis, and the second point is calculated using equations 1 and 2 .

$$
\begin{aligned}
& \theta=2 \pi \alpha \\
& \varphi=\operatorname{Arccos}(2 \beta-1)
\end{aligned}
$$

Where $\theta$ and $\varphi$ are spherical angles which are illustrated in Figure 1. $\alpha$ and $\beta$ are random numbers with a uniform distribution between 0 and 1 .

A Python script was utilized to setup the RVE in ABAQUS based on the output of the aforementioned MATLAB code. SFCs were created based on their coordinates and radius, and the contact interaction was defined on their outer surface. The remaining model preparation steps such as loading definitions and mesh generation were done using ABAQUS CAE. Figure 2 (b) shows the generated RVE for 1\% volume fraction.

Perfect bonding was assumed between the SFCs and the rubber matrix.

The simulation was broken down to two steps; the first step consisted of a coupled temperature-displacement analysis where mechanical loading was applied in one direction. This step is shown in Figure. 3a.

The second step was a coupled temperature-displacement analysis where a thermal loading was applied in the same direction as the mechanical loading in the previous step. For the thermal loading, one side of the RVE had a constant temperature, and its opposite side was specified to have free convection with air (Figure 3 (b)). In this study, eight tensile strain levels varying from $3.33 \%$ to $15 \%$ were applied on every sample. It should be noted that these tensile strains are in the elastic region of natural rubber.

\section{Results and Discussion}

\subsection{Samples}


RVEs were generated and studied with random distribution at three volume fractions of $1 \%$, $1.5 \%$, and $2 \%$. Five statistically equivalent RVEs were generated for each volume fraction, and the average of their properties was reported as a function of mechanical loading. The effective thermal conductivity of RVEs prior to any tensile strain was determined to be used for comparison purposes.

\subsection{Simulations and results}

Figure 4, shows the RVE under 3.33\% and 15\% tensile strain where the contour plots show the displacement along the loading direction. Figure 5 (a) shows the distribution of heat flux within an RVE with the volume fraction of $1 \%$ in the direction of loading. Figure 5 (b) shows a cross-section of temperature distribution within the RVE.

The next samples contain 1.5\% SCF (Figure 6 (a) shows the first sample of this volume fraction). Figure 6 (b) shows the first $\mathrm{RVE}$ of $\mathrm{VF}=1.5 \%$ with the generated mesh. Figure 7 shows the result of the first sample under minimum and maximum applied tensile strain. Figure 7 shows the displacement of the SCFs for the minimum and maximum applied tensile strains (i.e. $3.33 \%$ and $15 \%$, respectively). Figure 7 shows that SCFs' alignment change under mechanical loading, and their axes is oriented along the loading direction. This means that, the effective thermal conductivity of the RVE increases along the loading direction. 
For RVEs with VF=2\% the first sample is shown in Figure 8 (a) and its generated mesh is shown in Figure 8 (b). Displacement of the first RVE and SCFs for VF=2\% are demonstrated in Figure 9.

Figure 9 shows the RVE under minimum and maximum applied tensile strains $(3.33 \%$ and $15 \%$ respectively). Figure 9 illustrates how the alignment of SCFs is changed under loading. At $15 \%$ tensile strain, SCFs are oriented along the loading direction which improves the effective properties of the sample.

For evaluating the effective thermal properties, a Python script was used, which would calculate the average heat flux, stress, and strain for all the elements according to equations 3 to 5. For this purpose, for calculating the effective properties, the average of thermal and mechanical quantities of each element which can be extracted from output should be calculated by following equations.

$$
\begin{aligned}
& H F_{\text {ave }}=\sum_{1}^{N} \frac{H F_{i} \times v_{i}}{V} \\
& S_{\text {ave }}=\sum_{1}^{N} \frac{s_{i} \times v_{i}}{V} \\
& E_{e f f}=\sum_{1}^{N} \frac{e_{i} \times v_{i}}{V}
\end{aligned}
$$

Where HF denotes heat flux $\left(\mathrm{W} / \mathrm{m}^{2}\right), v_{i}$ is the volume of each element $\left(\mathrm{m}^{3}\right), \mathrm{S}$ is stress $(\mathrm{pa}), \mathrm{E}$ is strain, and $\mathrm{V}$ is the volume of the $\mathrm{RVE}\left(\mathrm{m}^{3}\right)$. Then, mean temperature of nodes which had free convection with air is calculated as it was discussed in section 2.

Then, using equation (3) the effective thermal conductivity was calculated:

$$
k_{e f f}\left(\frac{W}{m \cdot K}\right) \times \frac{\Delta T}{L(m)}=H F\left(\frac{W}{m 2}\right)
$$


Where $k_{e f f}$ is the effective thermal conductivity, $\Delta T$ is temperature difference between the two surfaces of the RVEs exposed to constant temperature and free convection, $\mathrm{L}$ is the length of the RVE after applying load, and HF is the heat flux according to equation (3). The effective elastic modulus can be calculated using the following equation.

$$
\text { Elastic Modulus }=\frac{S_{\text {ave }}}{E_{\text {ave }}}
$$

The effect of mechanical loading on the effective thermal conductivity of all samples was investigated and is shown in Figure 10.

The average effective thermal conductivity for $\mathrm{VF}=1 \%$ increased from $0.1621 \mathrm{~W} / \mathrm{m} . \mathrm{K}$ to 0.1644 $\mathrm{W} / \mathrm{m} . \mathrm{k}$ at $15 \%$ tensile strain along the direction of loading. This means the effective thermal conductivity increased by $1.42 \%$ after $15 \%$ tensile strain. Figure 10 explains that the average of the effective thermal conductivity for $\mathrm{VF}=1.5 \%$ increases with load, and its maximum is at the $15 \%$ tensile strain. The effective thermal conductivity of samples increased by $3.38 \%$ under $15 \%$ tensile strain. As shown in Figure 11, the average effective thermal conductivity of samples with $\mathrm{VF}=2 \%$ increased from $0.1794 \mathrm{~W} / \mathrm{m} . \mathrm{K}$ at the initial state to $0.1878 \mathrm{~W} / \mathrm{m} . \mathrm{K}$ at the tensile strain level of $15 \%$. This means the average of the effective thermal conductivity of these samples increased by $4.68 \%$ during these loadings.

As shown in Figures 4, 7, and 9, SCFs are reoriented during loading more towards the loading direction. The contrast between the thermal conductivity of SCFs is $100 \mathrm{~W} / \mathrm{m} . \mathrm{K}$ compared to the thermal conductivity of natural rubber $(0.14 \mathrm{~W} / \mathrm{m} . \mathrm{K})$ plays major role in the effective thermal conductivity of the composite. This leads to having more thermal channels (if we assume every SCF as a thermal channel due to their high thermal conductivity) in the direction of loading.

In this study, the trend of effective properties as a function of mechanical loading was investigated; therefore, the thermal resistance between SCFs and matrix is assumed to be negligible. In order to verify this study, one simulation taking into account the thermal resistance between SCFs and matrix was carried out with $R_{k}=8.3 \times 10^{-8} \mathrm{~m}^{2} \mathrm{~K} / \mathrm{W}$ reported by Nan et al. [32] for $\mathrm{VF}=1.5 \%$. The result of these simulations showed improvement in the effective thermal conductivity by $2.65 \%$, and the results showed the same trend, while without considering thermal resistance this improvement was $2.86 \%$. Considering the thermal resistance reduces the effective thermal conductivity in each strain, but it does not change the trend of improvement.

To compare this method to the analytical approach which was mentioned in the introduction, Mori-Tanaka method was used for samples with $\mathrm{VF}=1.5 \%$. Based on this method and increase of 4.05 percent was calculated in the effective thermal conductivity, whereas in the presented FEM 
simulation this was found to be $3.38 \%$, which suggests an agreement between the two techniques.

As illustrated in Figure 11, the average effective elastic modulus for $\mathrm{VF}=1 \%$ at $3.33 \%$ tensile strain was $1.6117 \mathrm{MPa}$ that increased to $1.62 \mathrm{MPa}$ at $15 \%$ tensile strain. The average effective elastic modulus increased by $0.51 \%$. Elasticity modulus was increased to its maximum at $15 \%$ tensile strain. This suggests that the SCFs are aligned along the direction of loading. According to Figure 11, the average of effective elastic modulus for $\mathrm{VF}=1.5 \%$ at $3.33 \%$ tensile strain was 1.6406 MPa that increased to $1.6547 \mathrm{MPa}$ at $15 \%$ tensile strain, which increased by $0.86 \%$. This figure demonstrates that the average of elastic modulus of $\mathrm{VF}=2 \%$ had increased by $0.78 \%$ during these loadings. As we discussed for figure 11, by applying mechanical loading on these composites, alignment of SCFs was altered, and they were oriented along the loading direction which led to a higher thermal conductivity along this direction. As well as thermal conductivity, elastic modulus of SCFs is greater than that of natural rubber (35 GPa for SCFs compare to 1.5 $\mathrm{MPa}$ for natural rubber); therefore, the alignment of SCFs in the composite is a significant factor for the effective thermal and mechanical properties. Consequently, having more SCF in the direction of loading, improved effective properties are to be expected, which is in agreement with what was presented in the results.

The effect of mechanical loading on the Poisson's ratio, $v_{32}$ is illustrated in Figure 12 which direction 3 is the direction of loading.

The effect of mechanical loading on the Poisson's ratio $v_{32}$ was investigated. As shown in Figure 12, Poisson's ratio varies for different samples because this parameter is highly depended on the distributions of SCFs. As the generation of these RVEs was discussed in the methodology, SCFs were generated randomly in the RVEs using Monte Carlo algorithm, distribution of SCFs were completely random, which led to have different Poisson's ratio for different samples.

\subsection{The average thermal and mechanical properties of RVEs}

Figure 13 shows the average of thermal conductivity for the three volume fractions which used in this study. Figure 13 illustrates that the average of all of volume fractions was increased during loading. 
Figure 14 shows the average of elastic modulus for the three volume fractions which were used in this study. Figure 14 suggests the average elastic modulus increases with loading, and it is greater for higher volume fractions.

\section{Conclusion}

In this study the effect of mechanical loading on the effective thermomechanical properties, elastic modulus, thermal conductivity and Poisson's ratio, was investigated. Monte Carlo algorithm was used to generate a random distribution of SCFs in natural rubber. Three different volume fractions were used with five statistically equivalent samples generated for each volume fraction. ABAQUS was used for simulating RVE models under eight mechanical loading scenarios. Two steps were prescribed for the simulations: mechanical loading followed by a thermal loading. A Python script was utilized for calculating the effective thermomechanical properties. Results show that the effective thermal conductivity of all samples increased during loadings, and the improvement of thermal conductivity in $\mathrm{VF}=2 \%$ was $4.68 \%$. Elastic modulus increased with mechanical loading, and an improvement of $0.78 \%$ was observed for $\mathrm{VF}=2 \%$ under maximum tensile strain. Poisson's ratio showed different behaviors for different samples which strongly depends on the alignment of SCFs. Results demonstrate that the alignment of SCFs changed under mechanical loading, which can explain the improvement of effective properties. The average effective thermal conductivity of RVEs with volume fraction value of $2 \%$ was found to be greater than that of natural rubber. By applying mechanical loading, the effective thermal conductivity of this sample increased by $4.68 \%$, which illustrate the effect of mechanical loading on the effective thermal conductivity.

\section{Acknowledgments}

The authors would like to acknowledge the funding for this Project from The Iran National Science Foundation (INSF). 


\section{References}

[1] B. e. Kilbride, J. Coleman, J. Fraysse, P. Fournet, M. Cadek, A. Drury, et al., "Experimental observation of scaling laws for alternating current and direct current conductivity in polymercarbon nanotube composite thin films," Journal of Applied Physics, vol. 92, pp. 4024-4030, 2002.

[2] M. Biercuk, M. C. Llaguno, M. Radosavljevic, J. Hyun, A. T. Johnson, and J. E. Fischer, "Carbon nanotube composites for thermal management," Applied physics letters, vol. 80, pp. 2767-2769, 2002.

[3] E. W. Wong, P. E. Sheehan, and C. M. Lieber, "Nanobeam mechanics: elasticity, strength, and toughness of nanorods and nanotubes," Science, vol. 277, pp. 1971-1975, 1997.

[4] S. lijima and T. Ichihashi, "Single-shell carbon nanotubes of 1-nm diameter," 1993.

[5] S. lijima, "Helical microtubules of graphitic carbon," nature, vol. 354, pp. 56-58, 1991.

[6] C. Yu, L. Shi, Z. Yao, D. Li, and A. Majumdar, "Thermal conductance and thermopower of an individual single-wall carbon nanotube," Nano letters, vol. 5, pp. 1842-1846, 2005.

[7] S. Berber, Y.-K. Kwon, and D. Tománek, "Unusually high thermal conductivity of carbon nanotubes," Physical review letters, vol. 84, p. 4613, 2000.

[8] M. Mahdavi, M. Baniassadi, M. Baghani, M. Dadmun, and M. Tehrani, "3D reconstruction of carbon nanotube networks from neutron scattering experiments," Nanotechnology, vol. 26, p. 385704, 2015.

[9] "Applied RVE Reconstruction and Homogenization of Heterogeneous Materials," ed.

[10] M. H. Al-Saleh and U. Sundararaj, "A review of vapor grown carbon nanofiber/polymer conductive composites," Carbon, vol. 47, pp. 2-22, 2009.

[11] N. Grossiord, J. Loos, O. Regev, and C. E. Koning, "Toolbox for dispersing carbon nanotubes into polymers to get conductive nanocomposites," Chemistry of materials, vol. 18, pp. 1089-1099, 2006.

[12] M. Taherzadeh, M. Baghani, M. Baniassadi, K. Abrinia, and M. Safdari, "Modeling and homogenization of shape memory polymer nanocomposites," Composites Part B: Engineering, vol. 91, pp. 36-43, 2016.

[13] Z. Han and A. Fina, "Thermal conductivity of carbon nanotubes and their polymer nanocomposites: a review," Progress in polymer science, vol. 36, pp. 914-944, 2011.

[14] D. Qian, E. C. Dickey, R. Andrews, and T. Rantell, "Load transfer and deformation mechanisms in carbon nanotube-polystyrene composites," Applied physics letters, vol. 76, pp. 2868-2870, 2000.

[15] S. Asiaei, A. A. Khatibi, M. Baniasadi, and M. Safdari, "Effects of carbon nanotubes geometrical distribution on electrical percolation of nanocomposites: a comprehensive approach," Journal of Reinforced Plastics and Composites, vol. 29, pp. 818-829, 2010.

[16] H. J. Park, A. Badakhsh, I. T. Im, M.-S. Kim, and C. W. Park, "Experimental study on the thermal and mechanical properties of MWCNT/polymer and Cu/polymer composites," Applied Thermal Engineering, vol. 107, pp. 907-917, 2016.

[17] J. A. King, K. W. Tucker, B. D. Vogt, E. H. Weber, and C. Quan, "Electrically and thermally conductive nylon 6, 6," Polymer composites, vol. 20, pp. 643-654, 1999.

[18] S. M. Lebedev and O. S. Gefle, "Evaluation of electric, morphological and thermal properties of thermally conductive polymer composites," Applied Thermal Engineering, vol. 91, pp. 875-882, 2015. 
[19] G. Zhang, J. Karger-Kocsis, and J. Zou, "Synergetic effect of carbon nanofibers and short carbon fibers on the mechanical and fracture properties of epoxy resin," Carbon, vol. 48, pp. 4289-4300, 2010.

[20] G. Mittal, V. Dhand, K. Y. Rhee, S.-J. Park, and W. R. Lee, "A review on carbon nanotubes and graphene as fillers in reinforced polymer nanocomposites," Journal of Industrial and Engineering Chemistry, vol. 21, pp. 11-25, 2015.

[21] C.-W. Nan, Z. Shi, and Y. Lin, "A simple model for thermal conductivity of carbon nanotubebased composites," Chemical Physics Letters, vol. 375, pp. 666-669, 2003.

[22] M. Baniassadi, A. Laachachi, A. Makradi, S. Belouettar, D. Ruch, R. Muller, et al., "Statistical continuum theory for the effective conductivity of carbon nanotubes filled polymer composites," Thermochimica Acta, vol. 520, pp. 33-37, 2011.

[23] Y. Benveniste, "A new approach to the application of Mori-Tanaka's theory in composite materials," Mechanics of materials, vol. 6, pp. 147-157, 1987.

[24] B. Mortazavi, M. Baniassadi, J. Bardon, and S. Ahzi, "Modeling of two-phase random composite materials by finite element, Mori-Tanaka and strong contrast methods," Composites Part B: Engineering, vol. 45, pp. 1117-1125, 2013.

[25] M. Mazrouei, H. Jokar, M. Baniassadi, K. Abrinia, and M. Haghighi-Yazdi, "Evaluating the effect of mechanical loading on the effective thermal conductivity of CNT/polymer nanocomposites," Journal of Computational and Theoretical Nanoscience, vol. 11, pp. 1738-1744, 2014.

[26] H. Zhang, Z. Zhang, and C. Breidt, "Comparison of short carbon fibre surface treatments on epoxy composites: I. Enhancement of the mechanical properties," Composites science and technology, vol. 64, pp. 2021-2029, 2004.

[27] N. Khun, H. Zhang, D. Sun, and J. Yang, "Tribological behaviors of binary and ternary epoxy composites functionalized with different microcapsules and reinforced by short carbon fibers," Wear, 2016.

[28] Z. Jiang, L. A. Gyurova, A. K. Schlarb, K. Friedrich, and Z. Zhang, "Study on friction and wear behavior of polyphenylene sulfide composites reinforced by short carbon fibers and sub-micro TiO 2 particles," Composites Science and Technology, vol. 68, pp. 734-742, 2008.

[29] D. R. Jones and M. F. Ashby, Engineering materials 2: an introduction to microstructures, processing and design: Butterworth-Heinemann, 2005.

[30] M. F. Ashby and D. Cebon, "Materials selection in mechanical design," Le Journal de Physique IV, vol. 3, pp. C7-1-C7-9, 1993.

[31] A. Ghazavizadeh, M. Baniassadi, M. Safdari, A. Atai, S. Ahzi, S. Patlazhan, et al., "Evaluating the effect of mechanical loading on the electrical percolation threshold of carbon nanotube reinforced polymers: A 3D Monte-Carlo study," Journal of Computational and Theoretical Nanoscience, vol. 8, pp. 2087-2099, 2011.

[32] C.-W. Nan, G. Liu, Y. Lin, and M. Li, "Interface effect on thermal conductivity of carbon nanotube composites," Applied Physics Letters, vol. 85, pp. 3549-3551, 2004. 
Figure 1. Spherical angles which are used in Monte-Carlo algorithm [25]

Figure 2. a) Generated SCFs for one of the samples which is used in this study by Monte-Carlo algorithm

b) The generated RVE in the finite element software (ABAQUS)

Figure 3. a) Applying mechanical loading on the first step of the simulation

b) Applying thermal loading on the second step of the simulation

Figure 4. a) Contours of displacement in deformed RVE with tensile strain $3.33 \%$ for the sample 1 of $\mathrm{VF}=1 \% \mathrm{~b}$ )

Deformed RVE with tensile strain $15 \%$ for the sample 1 of $\mathrm{VF}=1 \%$

Figure 5. a) Cross section of the RVE for heat flux in the direction of loading (sample 1 of $\mathrm{VF}=1 \%$ )

b) Temperature contour throughout the RVE for sample 1 of $\mathrm{VF}=1 \%$

Figure 6. a) Distribution of SCFs in the first RVE of VF=1.5\%

b) Generated mesh for the first sample of $\mathrm{VF}=1.5 \%$

Figure 7. The first RVE with $\mathrm{VF}=1.5 \%$ after a) the first (3.33\%) and b) final (15\%) tensile strains

Figure 8. a) Distribution of SCFs in the first RVE of $\mathrm{VF}=2 \%$

b) Generated mesh for the first RVE of $\mathrm{VF}=2 \%$

Figure 9. The first RVE with $\mathrm{VF}=2 \%$ after the a) $3.33 \%$ tensile strain and b) $15 \%$ tensile strain

Figure 10. The effect of mechanical loading on the effective thermal conductivity.

Figure 11. The effect of mechanical loading on the elastic modulus.

Figure 12. The effect of mechanical loading on the Poisson's ratio.

Figure 13. The average of thermal conductivity for three volume fractions which used in this study

Figure 14. The average of elastic modulus for three volume fractions which used in this study 


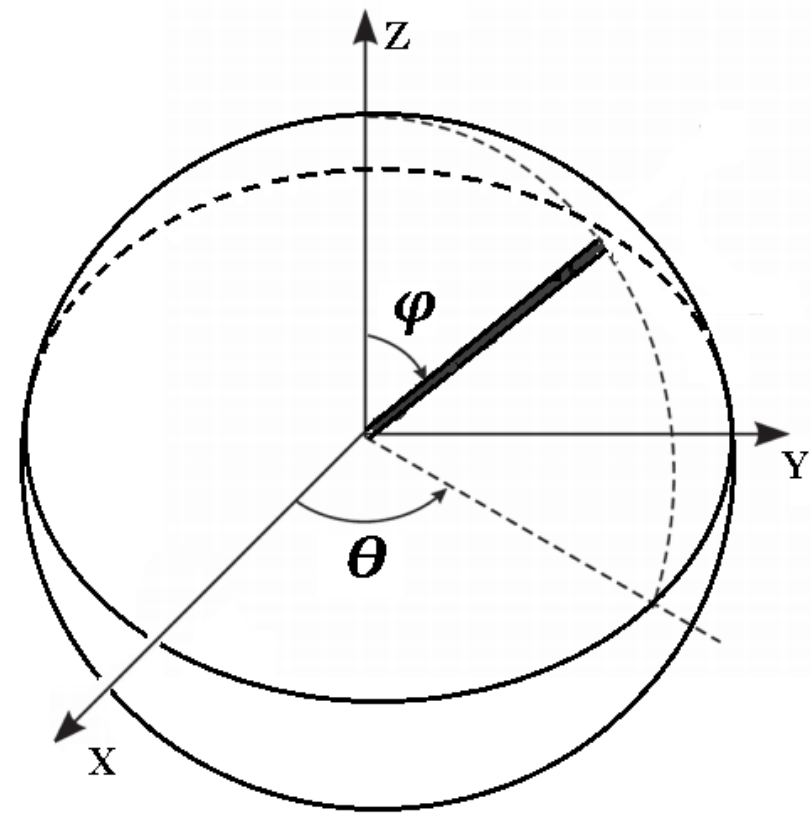

Figure 1. Spherical angles which are used in Monte-Carlo algorithm[25]

a)

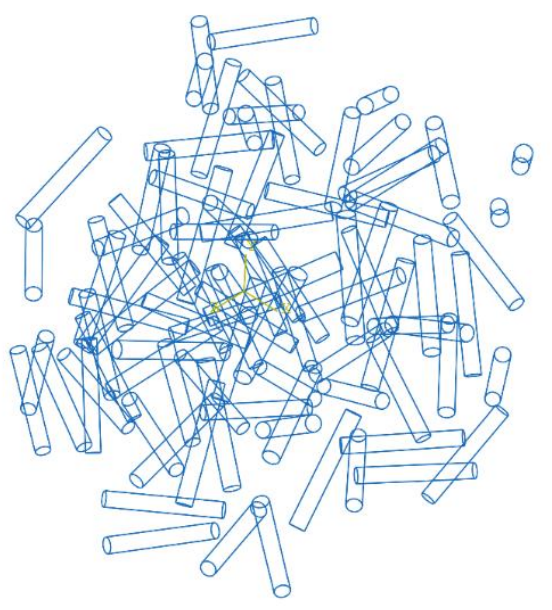

b)

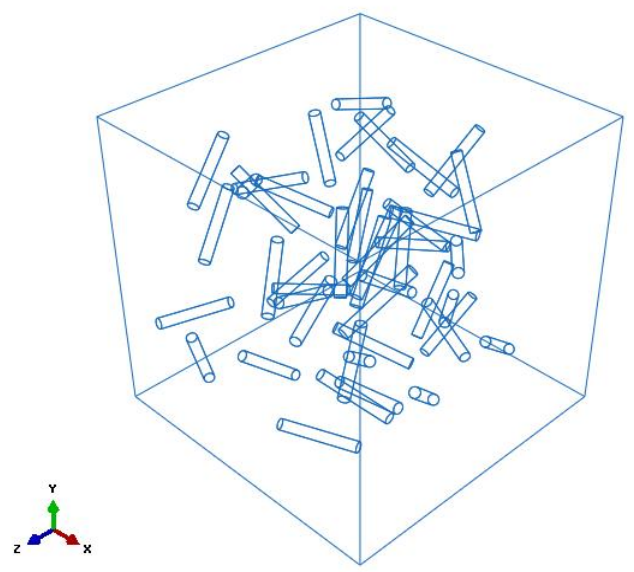

Figure 2. a) Generated SCFs for one of the samples which is used in this study by Monte-Carlo algorithm 
b) The generated RVE in the finite element software (ABAQUS)

a)

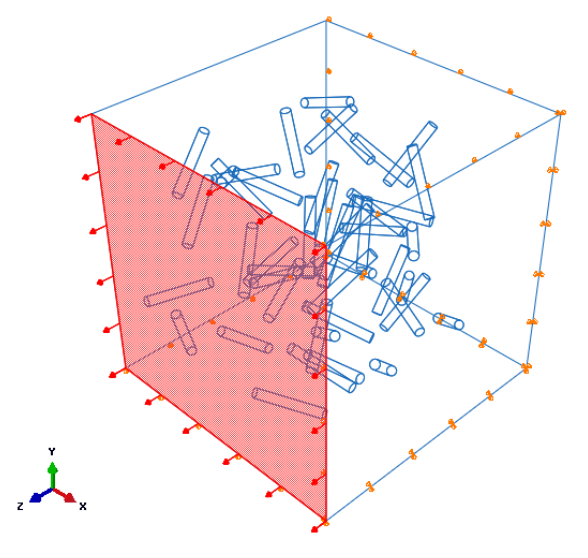

b)

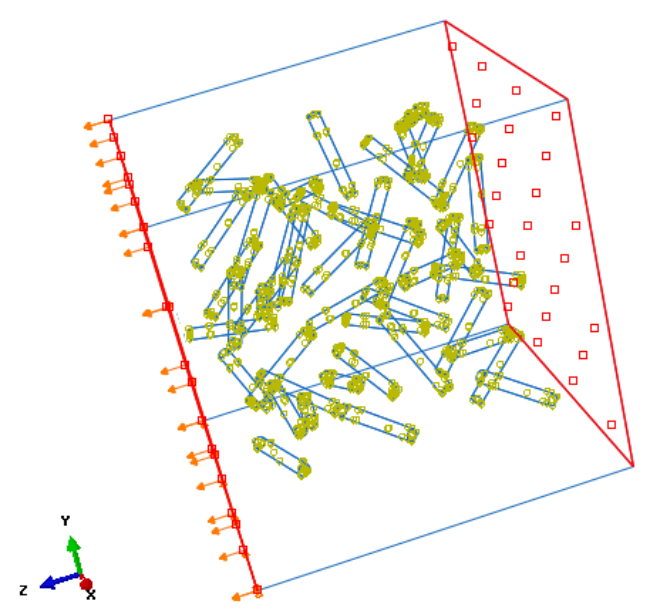

Figure 3. a) Applying mechanical loading on the first step of simulation

b) Applying thermal loading on the second step of simulation 


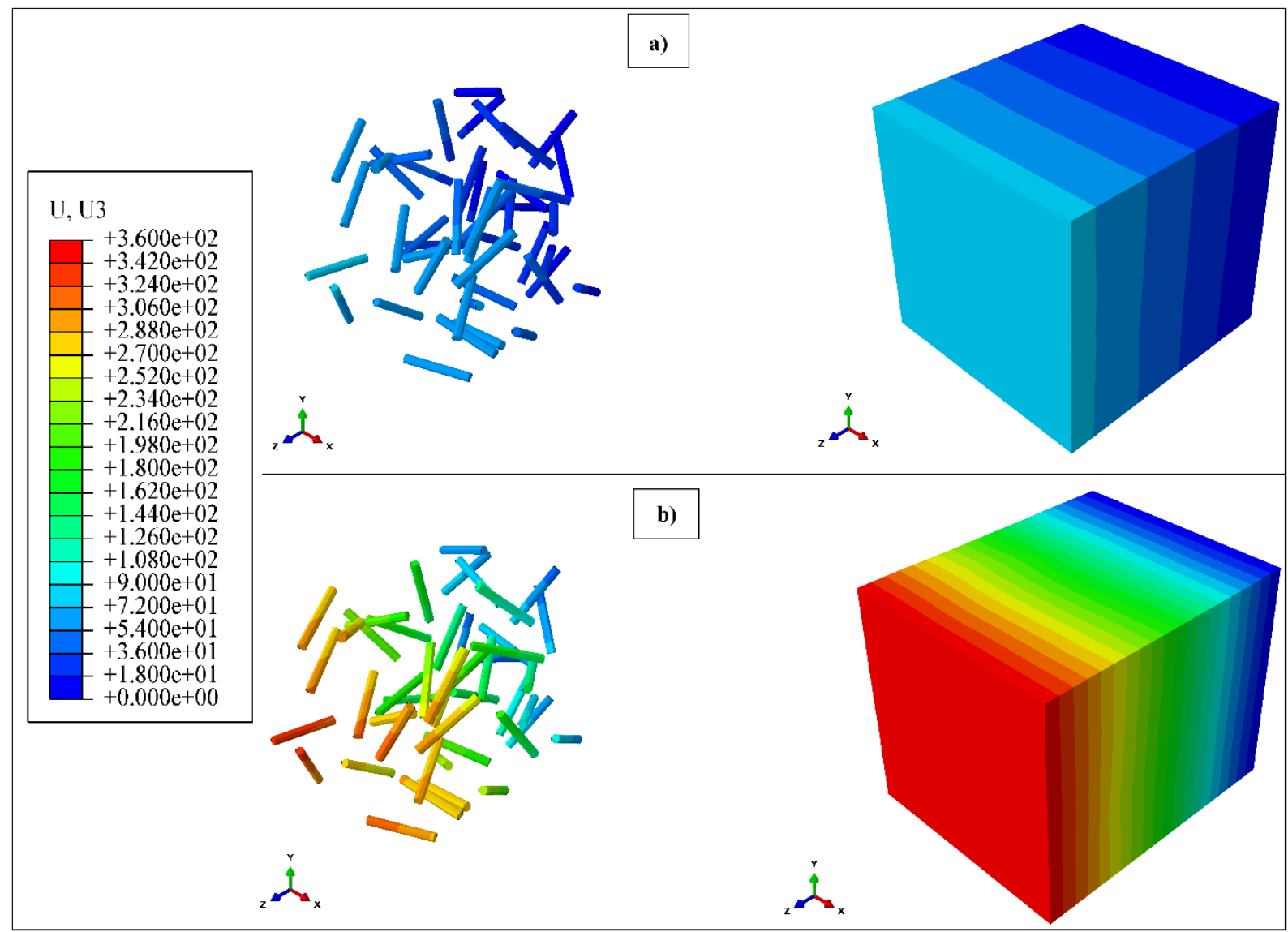

Figure 4. a) Contours of displacement in deformed RVE with tensile strain 3.33\% for the sample 1 of $\mathrm{VF}=1 \% \mathrm{~b}$ ) Deformed RVE with tensile strain $15 \%$ for the sample 1 of $\mathrm{VF}=1 \%$ 

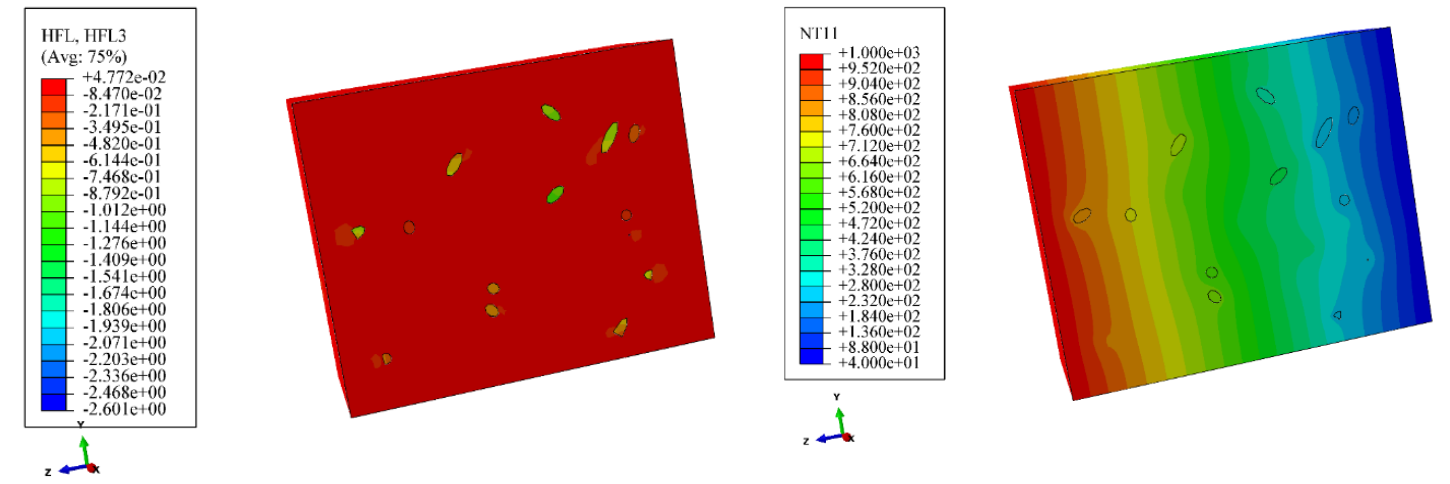

Figure 5. a) Cross section of the RVE for heat flux in the direction of loading (sample 1 of $V F=1 \%$ )

b) Temperature contour throughout the RVE for sample 1 of $\mathrm{VF}=1 \%$ 
a)

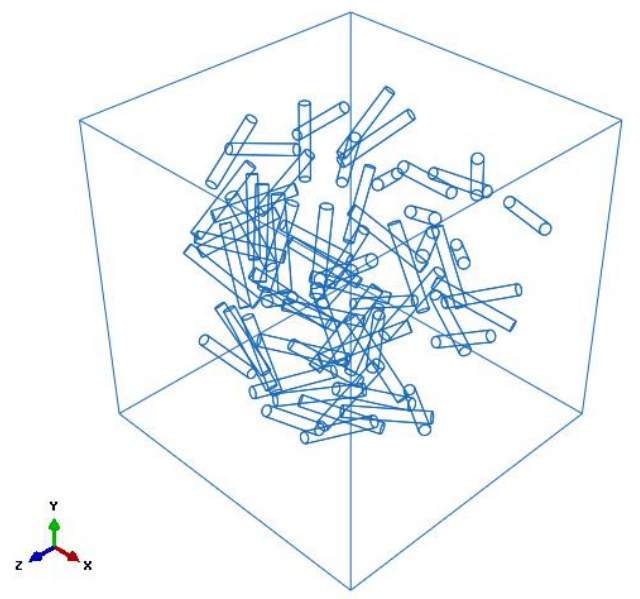

b)



Figure 6. a) Distribution of SCFs in the first RVE of VF=1.5\%

b) Generated mesh for the first sample of $\mathrm{VF}=1.5 \%$

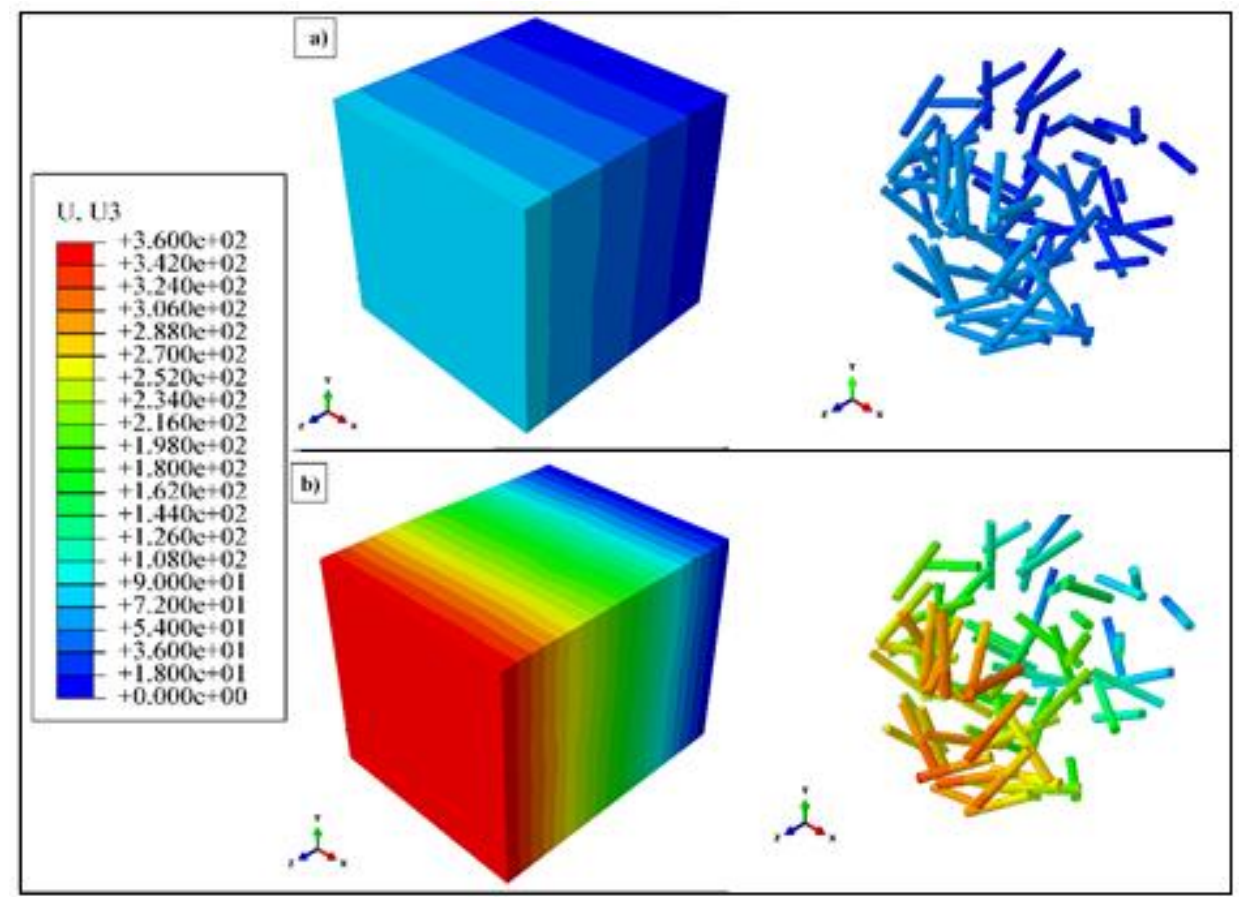

Figure 7. The first RVE with $\mathrm{VF}=1.5 \%$ after a) the first (3.33\%) and b) final (15\%) tensile strains 
a)

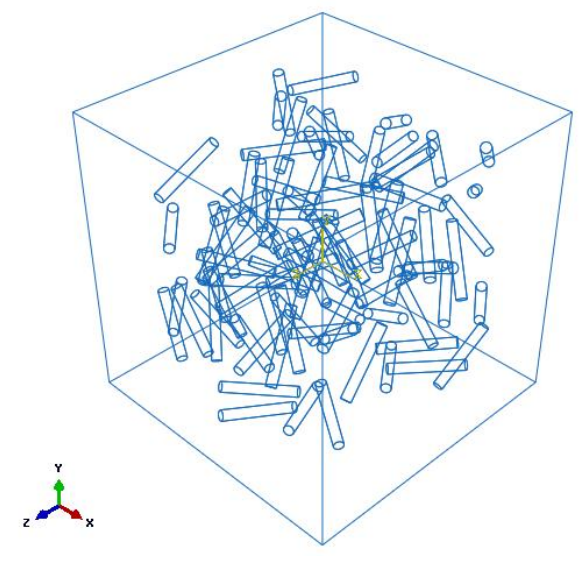

b)

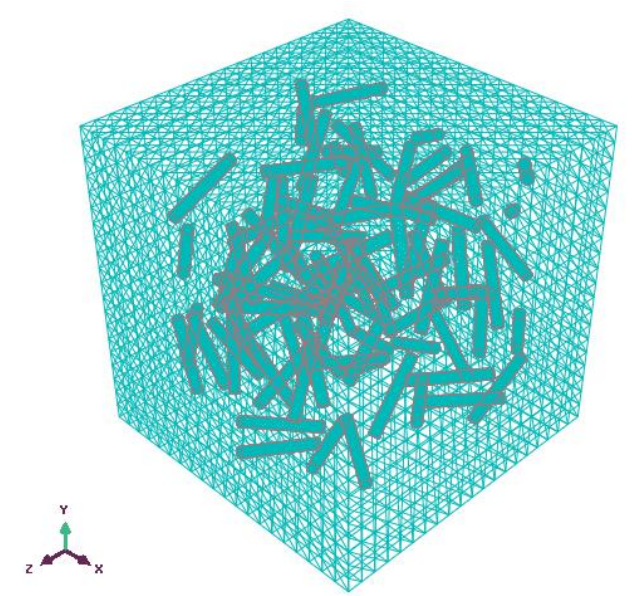

Figure 8. a) Distribution of SCFs in the first RVE of $\mathrm{VF}=2 \%$

b) Generated mesh for the first RVE of $\mathrm{VF}=2 \%$ 


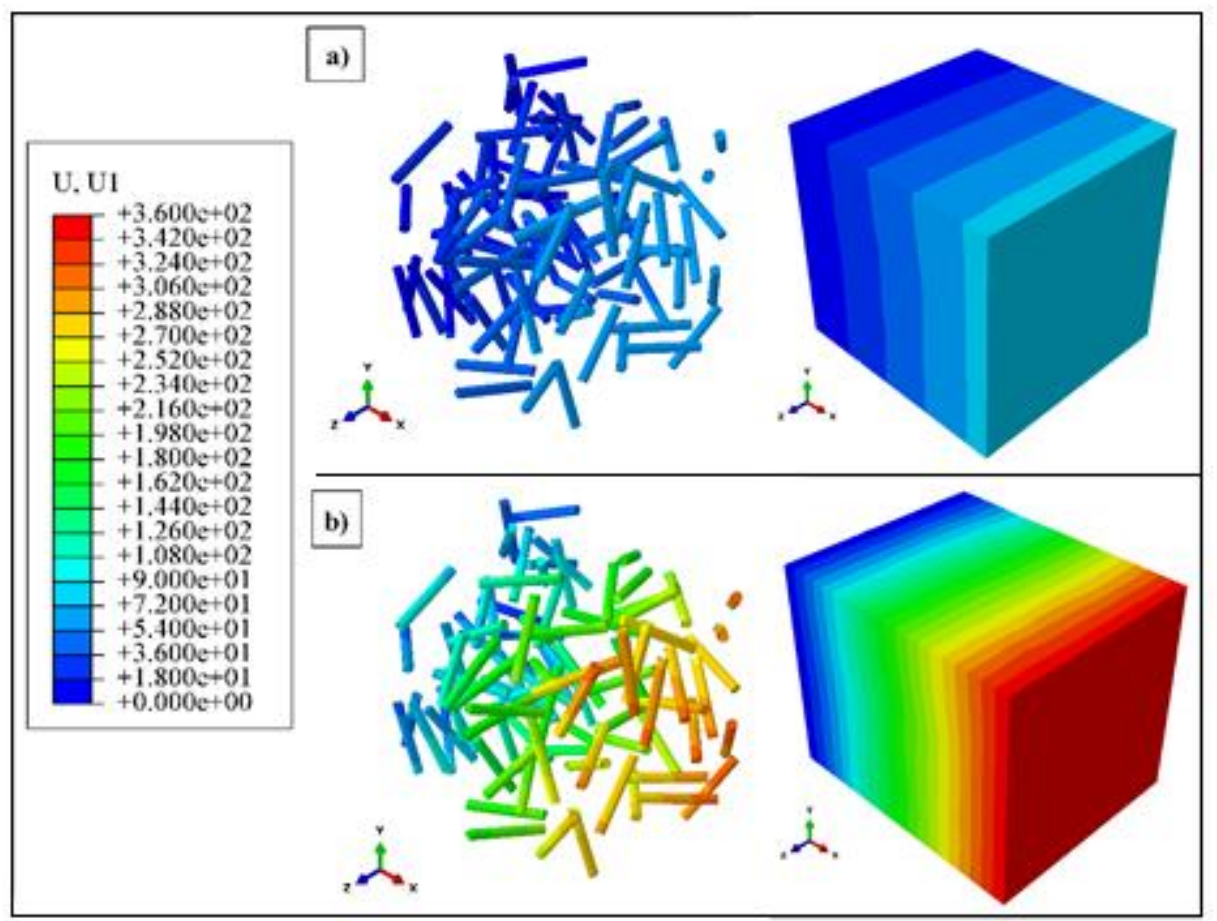

Figure 9. The first $\mathrm{RVE}$ with $\mathrm{VF}=2 \%$ after the a) $3.33 \%$ tensile strain and b) $15 \%$ tensile strain 


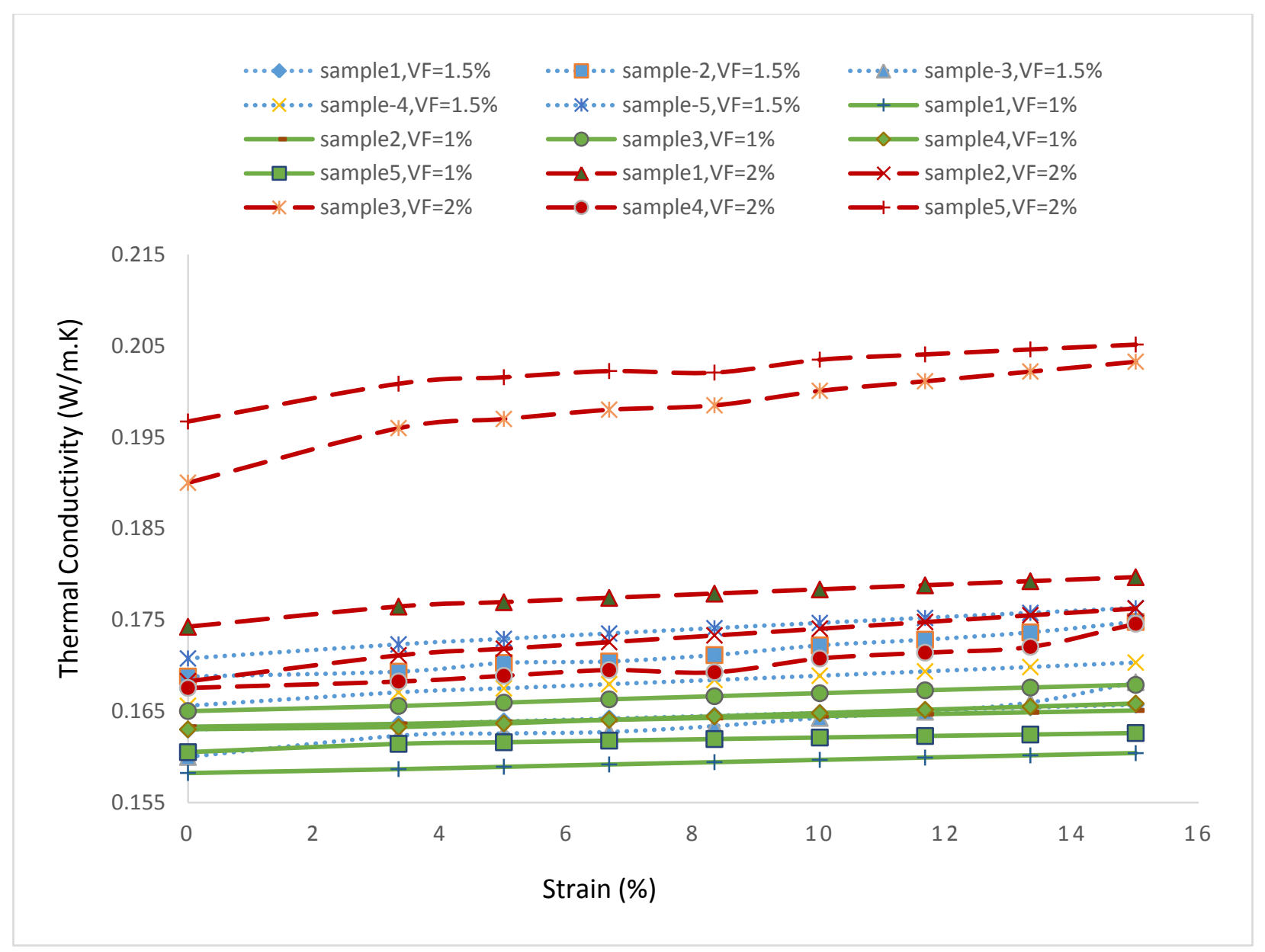

Figure 10. The effect of mechanical loading on the effective thermal conductivity. 


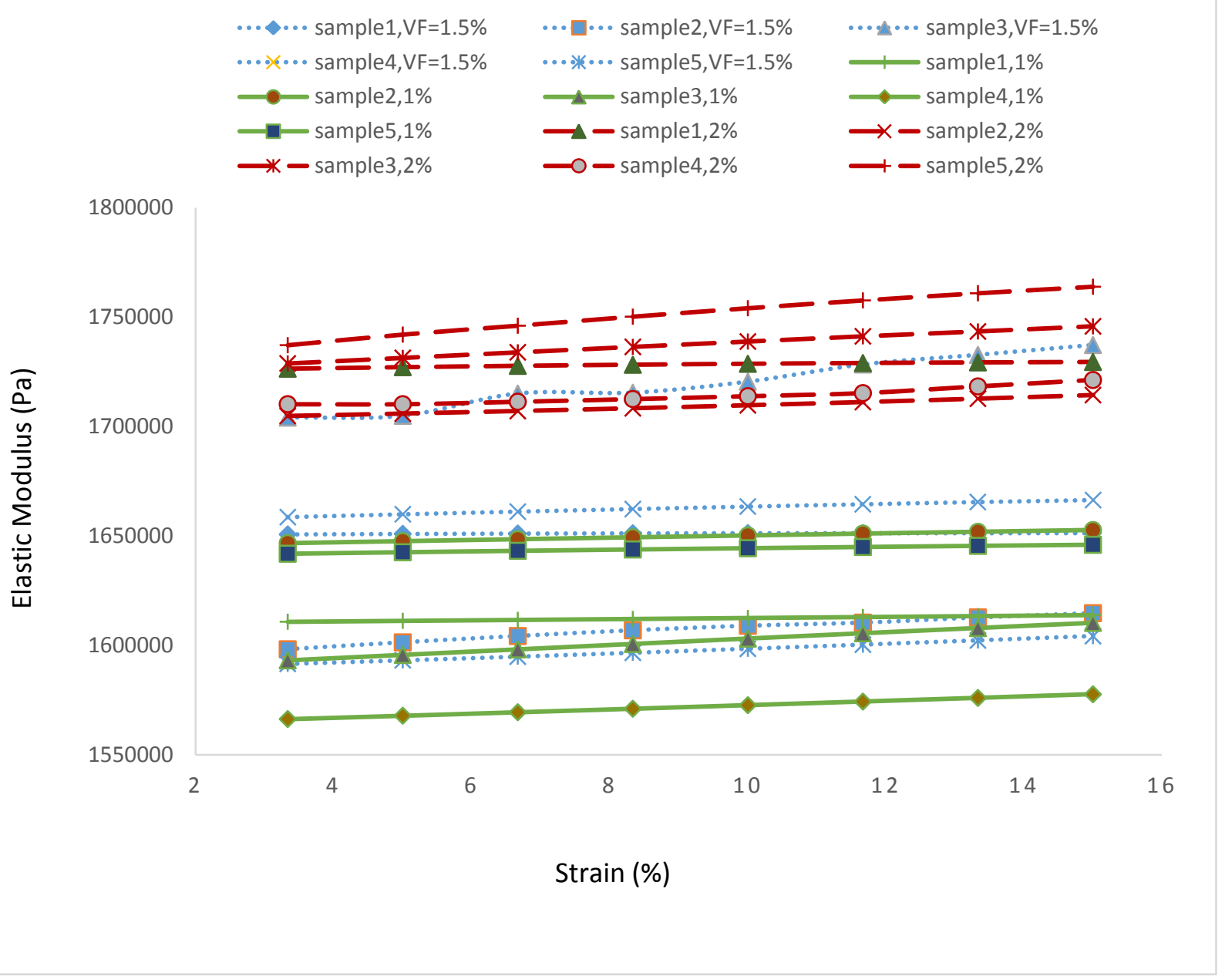

Figure 11. The effect of mechanical loading on the elastic modulus. 


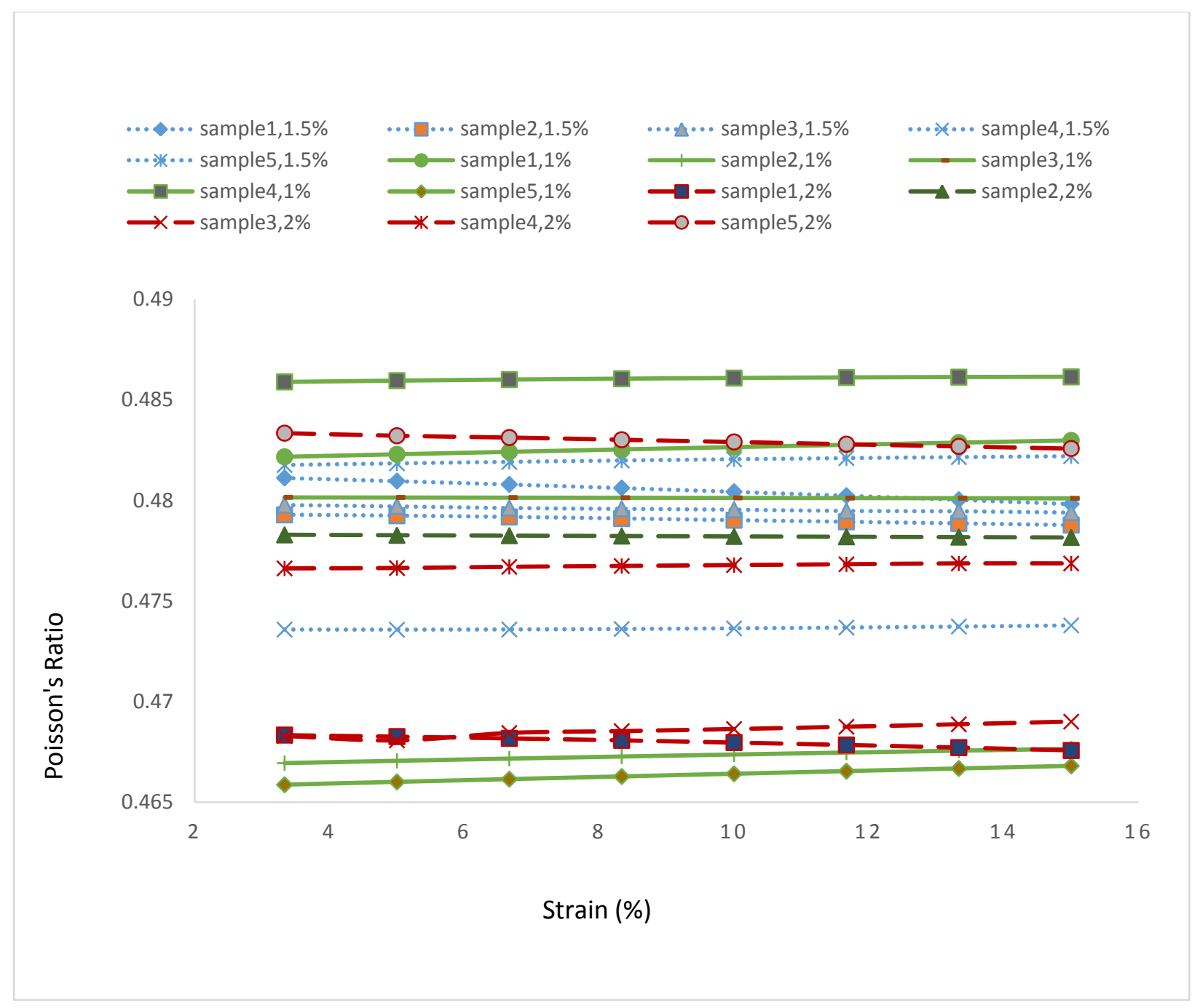

Figure 12. The effect of mechanical loading on the Poisson's ratio.

Average of thermal conductivity for three volume fractions

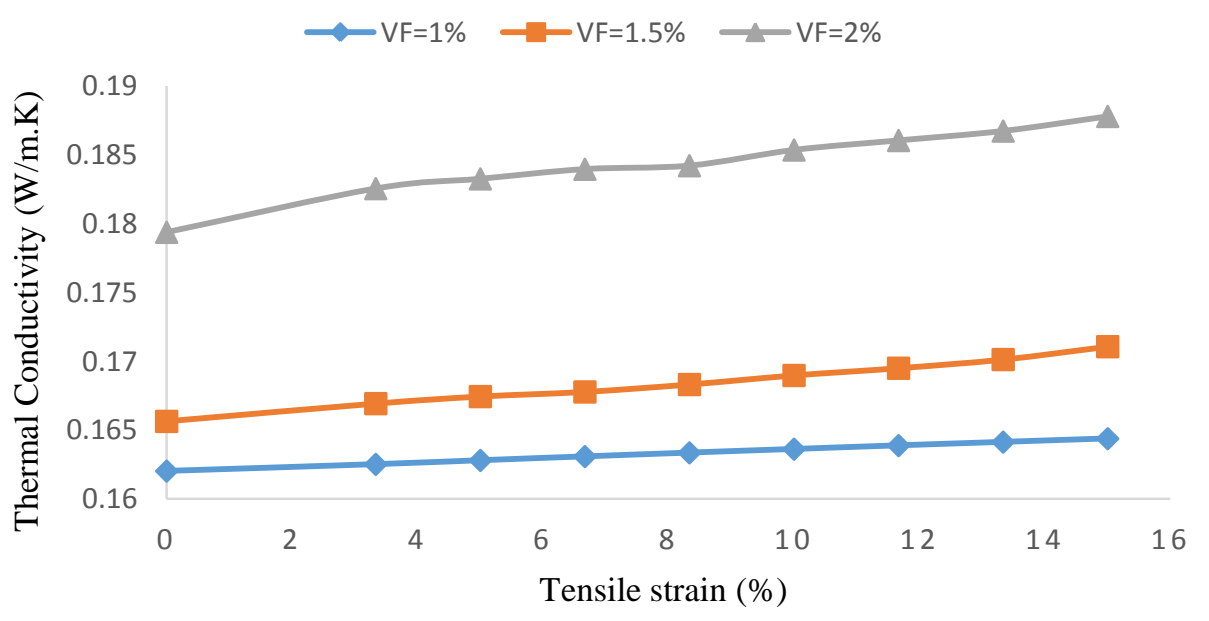


Figure 13. The average of thermal conductivity for three volume fractions which used in this study

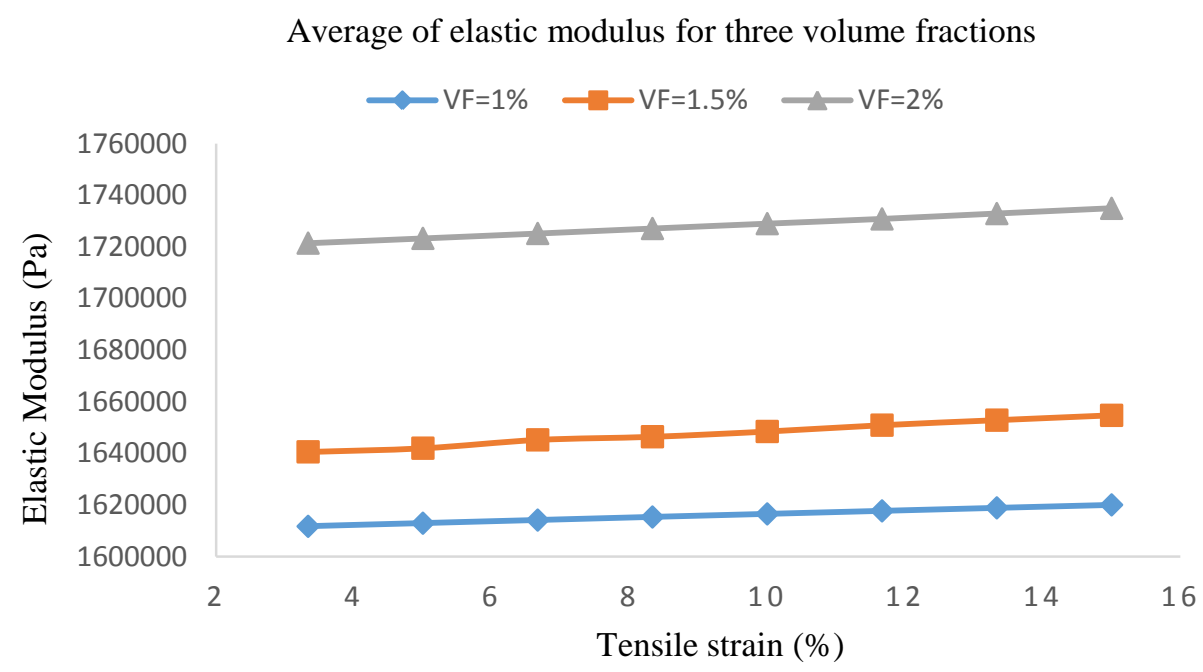

Figure 14. The average of elastic modulus for three volume fractions which used in this study 